\title{
Nodal prices determination with wind integration for radial distribution system
}

\author{
Manish Kumar ${ }^{1}$, Karimulla Piollisetti ${ }^{2}$, Ashwani Kumar ${ }^{3 *}$, K.S. Sandhu ${ }^{4}$ \\ 1,2,3,4 Department of Electrical Engineering, National Institute of Technology Kurukshetra, INDIA \\ ${ }^{*}$ Corresponding Author: e-mail: ashwani.k.sharma@nitkkr.ac.in, Tel.: +911744233389; fax: +911744238050
}

\begin{abstract}
With competitive electricity market operation, open access to the transmission and distribution network is essential for transparent and efficient market operation. Like transmission pricing, distribution network pricing must also be transparent and must include tile variations based on the change in the operating state of the system, integration of renewable sources and must be real time. In this paper, a distribution system nodal pricing scheme is proposed for radial distribution system with integration of wind power in the system. The main objective of the paper is: (i) an optimal power flow based approach for determination of nodal prices for distribution system, (ii) impact of wind generation on nodal prices. The results have been obtained for IEEE 33 bus test system.
\end{abstract}

Keywords: Distribution system, electricity market; nodal prices, wind power integration.

DOI: http://dx.doi.org/10.4314/ijest.v9i3.2

\section{Introduction}

Competitive electricity market sustainability and market efficiency is dependent on the transparent pricing structure. It is observed that the techniques used for the transmission pricing can also be applied to the distribution system such as nodal pricing, which is an efficient method for calculation of marginal cost of energy along with marginal cost of losses (Ghayeni and Ghazi, 2011). A dispersed generation is considered to allocate the losses using marginal loss coefficients and direct loss coefficients to determine the nodal prices in Mutale et al. (2000). Renewable energy sources have become essential part of the distribution network due to environmental constraints and regulatory policies worldwide. and it is essential to determine their impact on the prices at the nodes. Authors in Zhao et al. (2011) studied the impact of renewable energy integration on nodal prices considering the effect of intermittent load. Nodal pricing based method is also used for the location of DG as discussed in (Singh and Goswami (2006)). The analysis presented in Singh and Goswami (2006) is applied for loss minimization in Sotkiewicz and Vignolo (2006). In Zhao (2010) as well as Sotkiewicz and Vignolo (2012), the effect of solar and wind generation on distribution system prices were analyzed. The dynamic tariff concept is introduced in O'Connell et al. (2012) which is based on the distribution locational marginal prices to solve the congestion problems controlling the price values at different nodes. The analysis is extended in $\mathrm{Li}$ et al. (2014) to consider the inter-temporal characteristics of the flexible load. Tariff structure for distribution system with DG was proposed in Sooraj and Kumar (2015).

The nodal price behavior considering the ZIP and RIC loads, is considered in Sotkiewicz and Vignolo (2007) with the load flow based formulation. An optimal power flow based approach for distribution system nodal prices with seasonal load impact was presented in Polisetti and Kumar (2016). However, the impact of renewable energy with its cost was not considered. 


\section{Mathematical formulation}

In this section, an optimization model for determination of nodal prices is proposed with wind integration into the distribution network.

2.1 Optimal power flow model for nodal price: Optimal power flow (OPF) is formulated by minimizing the cost of power at substation and wind power cost which is given by the Equations (1- 7). The objective function includes the total operational cost of substation power and wind power cost function.

Minimize

Subject to

$$
\sum_{i}\left(a_{i} P_{G i}^{2}+b_{i} P_{G i}+c_{i}\right)+\left(a_{w i} P_{w i}^{2}+b_{w i} P_{w i}+c_{w i}\right)
$$

Load flow equations:

$$
\begin{gathered}
P_{G i}-P_{D i}+P_{w i}=V_{i} \sum_{j=1}^{n} V_{j}\left(G_{i j} \cos \theta_{i j}+B_{i j} \sin \theta_{i j}\right), \quad i \in S_{B} \\
Q_{R i}-Q_{D i}+Q_{w i}=V_{i} \sum_{j=1}^{n} V_{j}\left(G_{i j} \sin \theta_{i j}-B_{i j} \cos \theta_{i j}\right), \quad i \in S_{B}
\end{gathered}
$$

Power generation limits, voltage limits and flow limits:

$$
\begin{aligned}
& P_{G i}^{\min } \leq P_{G i} \leq P_{G i}^{\max }, i \in S_{G} \\
& Q_{R i}^{\min } \leq Q_{R i} \leq Q_{R i}^{\max }, i \in S_{R} \\
& V_{i}^{\min } \leq V_{i} \leq V_{i}^{\max }, i \in S_{B} \\
& \left|P_{l}\right|=\left|P_{i j}\right|=\left|V_{i} V_{j}\left(G_{i j} \cos \theta_{i j}+B_{i j} \sin \theta_{i j}\right)-V_{i}^{2} G_{i j}\right| \leq P_{l}^{\max }, l \in S_{L}
\end{aligned}
$$

where $S_{B} S_{G}, S_{R}$ and $S_{l}$ represents the set of nodes, generators, reactive power sources and lines respectively. The voltages, generated real power, generated reactive power, real power demand and reactive power demand are represented by $V_{i}, P_{G i}, Q_{R i}, P_{D i}$ and $Q_{D i} . \theta_{i}$ is the angle at node $\mathrm{i}$, where as $G_{i j}$ and $B_{i j}$ are the real and imaginary parts of the admittance of line connected between $\mathrm{i}$ and $\mathrm{j}$ nodes, $P_{l}^{\max }$ is the maximum power flow limit in line $l$. Here $P_{w i}$ is the output power from the wind turbine generator.

Here the values of operational cost coefficients are taken as $a_{i}=0.01, b_{i}=40, c_{i}=9$ and the wind cost coefficients (De Oliveira-De Jesus and Ponce de Leao, 2005) are $a_{w i}=0.0027, b_{w i}=17.83, c_{w i}=4.46$.

2.2 Nodal price for distribution network: Nodal prices for distribution system can be derived using Marginal Loss Coefficients (MLCs) to get price at each node of the distribution system. MLCs are coefficients which indicate the marginal or incremental deviation in total active power loss due to the changes in active and reactive power injections at a particular node of the system. The active and reactive power MLCs are:

$$
\begin{gathered}
\rho_{P i}=\frac{\partial L}{\partial P_{i}} \\
\rho_{Q i}=\frac{\partial L}{\partial Q_{i}}
\end{gathered}
$$

where

$L:$ The total power loss

$\rho_{P i}$ : The active power MLC at node $i$ of the system

$\rho_{Q i}$ : The reactive power MLC at node $i$ of the system

The power supply point (PSP) is defined as the connection between transmission and distribution systems. The price at PSP is indicated by $\lambda$ (USD/MWh) which depends on solution of optimal power flow and is given by the following relation.

$$
\lambda=2 a_{i} P_{G i}+b_{i}
$$

Nodal prices for active and reactive power at all nodes can be found by using following relations

$$
\begin{aligned}
& \mathrm{N}_{\mathrm{Pi}}=\lambda\left(1+\rho_{\mathrm{Pi}}\right) \\
& \mathrm{N}_{\mathrm{Qi}}=i \rho_{\mathrm{Qi}}
\end{aligned}
$$

where , $N_{P i}(\$ / \mathrm{MWh})$ and $N_{Q i}(\$ / \mathrm{MVARh})$ are the active and reactive power nodal prices at node $i$ of the system respectively. The reactive power price at PSP is taken as zero.

2.3 Determination of marginal loss coefficients: The active and reactive power Marginal Loss Coefficients (MLCs) are determined using the Jacobian matrix method. This method of determining the MLCs was proposed by the authors in (De OliveiraDe Jesus and Ponce de Leao, 2005). The following sets of linear equations are utilized in this method. 


$$
\begin{aligned}
& {\left[\frac{\rho_{P i}}{\rho_{Q i}}\right]=\left[\begin{array}{ccc|ccc}
\frac{\partial P_{1} \partial P_{2}}{\partial \theta_{1} \partial \theta_{1}} & \cdots & \frac{\partial P_{n}}{\partial \theta_{1}} & \frac{\partial Q_{1} \partial Q_{2}}{\partial \theta_{1} \partial \theta_{1}} & \cdots & \frac{\partial Q_{n}}{\partial \theta_{1}} \\
\vdots & \ddots & \vdots & \vdots & \ddots & \vdots \\
\frac{\partial P_{1} \partial P_{2}}{\partial \theta_{n} \partial \theta_{n}} & \cdots & \frac{\partial P_{n}}{\partial \theta_{n}} \\
\frac{\partial P_{1} \partial P_{2}}{\partial V_{1} \partial V_{1}} & \cdots & \frac{\partial P_{n}}{\partial V_{1}} & \frac{\partial Q_{2}}{\partial \theta_{n} \partial \theta_{n}} & \cdots & \frac{\partial Q_{n}}{\partial \theta_{n}} \\
\vdots & \frac{\partial Q_{1} \partial Q_{2}}{\partial V_{1} \partial V_{1}} & \cdots & \frac{\partial Q_{n}}{\partial V_{1}} \\
\vdots & \vdots & \vdots & \vdots \\
\frac{\partial P_{1} \partial P_{2}}{\partial V_{n} \partial V_{n}} & \cdots & \frac{\partial P_{n}}{\partial V_{n}} & \frac{\partial Q_{1} \partial Q_{2}}{\partial V_{n} \partial V_{n}} & \cdots & \frac{\partial Q_{n}}{\partial V_{n}}
\end{array}\right]^{-1}\left[\begin{array}{c}
\frac{\partial L}{\partial \theta_{1}} \\
\vdots \\
\frac{\partial L}{\partial \theta_{n}} \\
\frac{\partial L}{\partial V_{1}} \\
\vdots \\
\frac{\partial L}{\partial V_{n}}
\end{array}\right]} \\
& \frac{\partial P_{i}}{\partial \theta_{j}}=V_{i} V_{j}\left[G_{i j} \sin \left(\theta_{i}-\theta_{j}\right)-B_{i j} \cos \left(\theta_{i}-\theta_{j}\right)\right] \\
& \frac{\partial P_{i}}{\partial \theta_{i}}=-B_{i i} V_{i}^{2}-\sum_{j=1}^{n} V_{i} V_{j}\left[G_{i j} \sin \left(\theta_{i}-\theta_{j}\right)-B_{i j} \cos \left(\theta_{i}-\theta_{j}\right)\right] \\
& \frac{\partial P_{i}}{\partial V_{j}}=V_{i}\left[G_{i j} \cos \left(\theta_{i}-\theta_{j}\right)+B_{i j} \sin \left(\theta_{i}-\theta_{j}\right)\right] \\
& \frac{\partial P_{i}}{\partial V_{i}}=G_{i i} V_{i}+\sum_{j=1}^{n} V_{j}\left[G_{i j} \cos \left(\theta_{i}-\theta_{j}\right)+B_{i j} \sin \left(\theta_{i}-\theta_{j}\right)\right] \\
& \frac{\partial Q_{i}}{\partial \theta_{j}}=-V_{i} V_{j}\left[G_{i j} \cos \left(\theta_{i}-\theta_{j}\right)+B_{i j} \sin \left(\theta_{i}-\theta_{j}\right)\right] \\
& \frac{\partial Q_{i}}{\partial \theta_{i}}=-G_{i i} V_{i}^{2}+\sum_{j=1}^{n} V_{i} V_{j}\left[G_{i j} \cos \left(\theta_{i}-\theta_{j}\right)+B_{i j} \sin \left(\theta_{i}-\theta_{j}\right)\right] \\
& \frac{\partial Q_{i}}{\partial V_{j}}=V_{i}\left[G_{i j} \sin \left(\theta_{i}-\theta_{j}\right)-B_{i j} \cos \left(\theta_{i}-\theta_{j}\right)\right] \\
& \frac{\partial Q_{i}}{\partial V_{i}}=-B_{i i} V_{i}+\sum_{j=1}^{n} V_{j}\left[G_{i j} \sin \left(\theta_{i}-\theta_{j}\right)-B_{i j} \cos \left(\theta_{i}-\theta_{j}\right)\right]
\end{aligned}
$$

The total loss of the distribution system is given by

$$
L=\frac{1}{2} \sum_{i=1}^{n} \sum_{j=1}^{n} G_{i j}\left[V_{i}^{2}+V_{j}^{2}-2 V_{i} V_{j} \cos \left(\theta_{i}-\theta_{j}\right)\right]
$$

From this equation, the derivative of loss with respect to voltage angles and magnitudes can be derived as follows:

$$
\begin{aligned}
& \frac{\partial L}{\partial \theta_{i}}=2 \sum_{j=1}^{n} V_{i} V_{j} G_{i j} \sin \left(\theta_{i}-\theta_{j}\right) \\
& \frac{\partial L}{\partial V_{i}}=2 \sum_{j=1}^{n} G_{i j}\left[V_{i}-V_{j} \cos \left(\theta_{i}-\theta_{j}\right)\right]
\end{aligned}
$$

where

$V_{i}, V_{j}$ : The voltage magnitudes at the sending and receiving end nodes respectively

$\theta_{i}, \theta_{j}$ : The voltage angles at the sending and receiving end nodes respectively

$G_{i j}$ : The conductance of the $i-j^{\text {th }}$ element of the Y-bus matrix

$B_{i j}$ : The susceptance of the $i-j^{\text {th }}$ element of the Y-bus matrix

$n$ : The total number of nodes in the system.

2.4 Reconciliated Marginal Loss Coefficients: The approximate total losses of the system can also be obtained from the MLCs as follows:

$$
L_{\text {approx }}=\sum_{i=1}^{n}\left[\rho_{P i} \cdot P_{i}+\rho_{Q i} \cdot Q_{i}\right]
$$

where $P_{i}$ and $Q_{i}$ are the active and reactive power injections at node $i$ respectively. As concluded by authors in De Oliveira-De Jesus and Ponce de Leao (2005), it was observed that the value of losses approximated using MLCs were almost as twice as the actual losses of the system. This leads to over estimation of the nodal prices of the system. Hence, the MLCs have to be adjusted in order to estimate the exact cost of losses, which is done using the factor of reconciliation $(R f)$.

$$
R f=\frac{L}{L_{\text {approx }}}
$$

With the application of reconciliation, the new active and reactive nodal prices are obtained as shown below:

$$
\begin{aligned}
& N_{P i}=\lambda+\lambda \cdot R f \cdot \rho_{P i}=\lambda\left(1+R f \cdot \rho_{P i}\right) \\
& N_{Q i}=\lambda \cdot R f \cdot \rho_{Q i}
\end{aligned}
$$

\section{Optimal location for Wind turbine power source}

Sensitivity based indices have been used in the recent past to obtain the optimum location for placing the DGs in the distribution system. In this thesis, voltage sensitivity index (VSI) has been utilized to obtain the most optimum location for wind turbine placement in the system. 
3.1 Voltage Sensitivity Index (VSI) (Murthy and Kumar, 2014): Sensitivity based indices have been used in the recent past to obtain the optimum location for placing the DGs in the distribution system. In this thesis, voltage sensitivity index (VSI) has been utilized to obtain the most optimum location for wind turbine placement in the system. Voltage sensitivity index is a numerical solution in which the operator knows how close the system is to collapse, the lower the sensitivity index, the closer the bus to collapse hence in this method the bus with low sensitivity is selected for the placement of capacitor. Voltage sensitivity index of bus $i$ is given as follows

$$
V S I_{i}=\sqrt{\frac{\sum_{k=1}^{n}\left(1-V_{k}\right)^{2}}{n}} k \in S_{B},
$$

$V S I_{i}$ is calculated by placing a DG with the size equal to $25 \%$ of the total feeder loading at node $i$.

Figure 3 shows the voltage sensitivity index profile for the considered 33 bus test system, in which bus 18 is having highest voltage sensitivity index hence this method indicates the bus 18 is the optimal location for wind based DG placement 33 bus radial system.

Using the Weibull parameters, a large number of wind samples which are Weibull distributed can be produced using Monte Carlo simulation (MCS). Since the relationship between wind speed and power production is known from Equation (20), a large number of power samples can also be obtained. The number of samples of MCS is usually more than 10000. Hence, the number of wind power scenarios to be applied to the distribution system is also of the same order. Such a large number of scenarios make the analysis a tasking one. In order to reduce the computational burden of the program developed, the number of scenarios is reduced using a process known as wind speed leveling. The wind turbine will operate from cut-in speed to the cut-out speed specified. The entire range of wind speed from the cut-in speed to the cut-out speed is known as the operating range of the wind turbine. The number of wind speed samples can be grouped into various wind speed ranges specified. Each wind speed sample from the Weibull distribution function will be falling within any one of the wind speed ranges or levels specified.

The wind speed is divided into various levels and power outputs of each level are obtained. The wind speed samples are clustered into levels of wind speeds. Hence, the power outputs corresponding to these wind speeds are also clustered according to wind speed levels. The mean value of power output of each wind speed level is calculated. Then, the probability of occurrence of every wind speed level is calculated by Equation (30).

$$
\operatorname{prob}_{j}=\frac{N W_{j}}{T W}
$$

where $\operatorname{prob}_{j}$ is the probability of occurrence of wind speed level $j, N W_{j}$ is the number of wind speed samples in level $j$ and $T W$ is the total number of wind speed samples. The mean power output of each wind level is multiplied by the probability of occurrence of that level to get that actual wind turbine output for that level. This will provide an accurate representation of the actual wind power output for that wind speed range. The procedure of wind speed levelling is shown graphically in Figure 1.

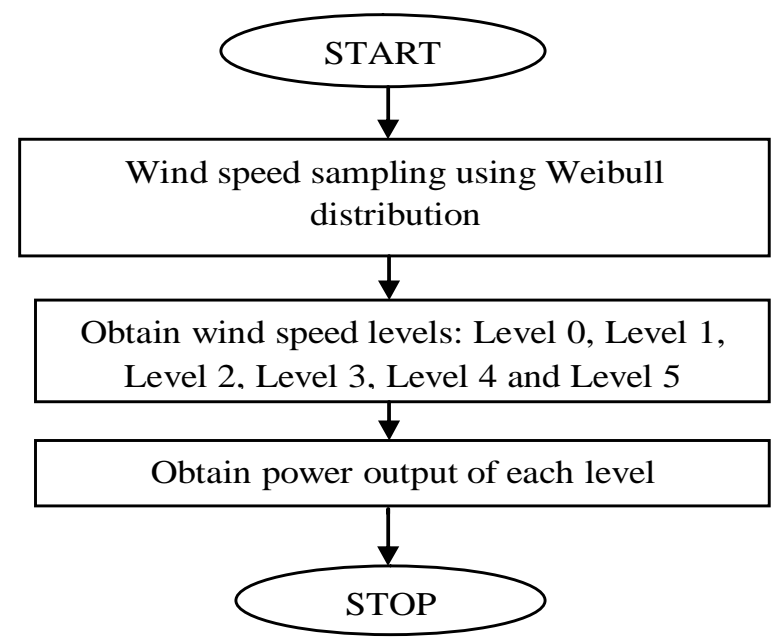

Figure1. Wind speed sampling and leveling

\section{Results and discussion}

The studies were conducted on the IEEE 33 bus radial and mesh distribution system. The base power of the system is 100 MVA and the base voltage is $12.66 \mathrm{KV}$. The total connected active power load is $3.72 \mathrm{MW}$ and reactive power load is 2.30 MVAR. An optimal nodal pricing has been obtained considering the seasonal loads, ZIP load and RIC load with the integration of wind energy. 
The specifications of the wind turbine selected and the Weibull parameters are given in Murthy and Kumar ( 2014). From the Weibull parameters, the samples of wind speed are obtained using MCS based sampling. Figure 2 shows a comparison of the scatter diagrams of wind speed vs power output curve of linear and quadratic models.

Table1. Parameter of Wind turbine

\begin{tabular}{|l|l|l|l|l|l|}
\hline $\begin{array}{l}\text { Rated Power } \\
\left(P_{r} \text { in MW }\right)\end{array}$ & $\begin{array}{l}\text { Cut-in speed } \\
\left(v_{c i} \text { in } \mathrm{m} / \mathrm{s}\right)\end{array}$ & $\begin{array}{l}\text { Rated speed } \\
\left(v_{r} \text { in } \mathrm{m} / \mathrm{s}\right)\end{array}$ & $\begin{array}{l}\text { Cut-out speed } \\
\left(v_{c o} \text { in } \mathrm{m} / \mathrm{s}\right)\end{array}$ & $\begin{array}{l}\text { Shape parameter } \\
(k)\end{array}$ & $\begin{array}{l}\text { Scale parameter } \\
(c \text { in } \mathrm{m} / \mathrm{s})\end{array}$ \\
\hline 2.00 & 3 & 11.5 & 20 & 1.75 & 8.78 \\
\hline
\end{tabular}

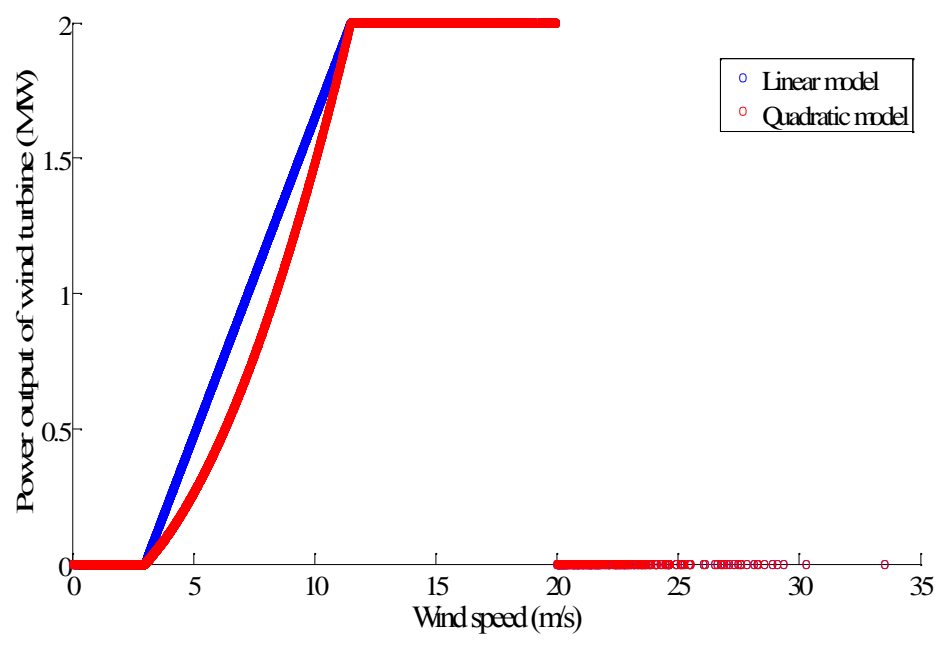

Figure2. Comparison of scatter diagrams of wind speed vs power output of linear and quadratic model

\subsection{Levels of Wind Speed}

The number of wind speed levels is chosen as five. The wind speed levels and the corresponding speed range are shown in Table 2. Level 0 corresponds to the base case where no wind turbine is integrated. The results obtained in the further sections are obtained using the linear power model discussed in the previous sections.

Table 2. Wind speed levels and the corresponding power outputs

\begin{tabular}{|c|c|l|l|l|l|c|}
\hline $\begin{array}{l}\text { Level } \\
\text { index }\end{array}$ & $\begin{array}{c}\text { Speed } \\
\text { range } \\
(\mathrm{m} / \mathrm{s})\end{array}$ & $\begin{array}{c}\text { Mean } \\
\text { power } \\
\text { output } \\
(\mathrm{MW})\end{array}$ & $\begin{array}{c}\text { Percentage of } \\
\text { rated turbine } \\
\text { power output } \\
(\%)\end{array}$ & $\begin{array}{l}\text { Probability of } \\
\text { occurrence }\end{array}$ & $\begin{array}{l}\text { Actual power } \\
\text { output (MW) }\end{array}$ & $\begin{array}{l}\text { Penetration level } \\
(\%)\end{array}$ \\
\hline 0 & $0-3$ & 0 & 0 & 0.1416 & 0 & 0.0000 \\
\hline 1 & $3-5$ & 0.2408 & 12.0399 & 0.1683 & 0.0405 & 1.0887 \\
\hline 2 & $5-8$ & 0.8108 & 40.5411 & 0.2636 & 0.2137 & 5.7446 \\
\hline 3 & $8-11.5$ & 1.5564 & 77.8208 & 0.225 & 0.3502 & 9.4139 \\
\hline 4 & $11.5-15$ & 2 & 100 & 0.1219 & 0.2437 & 6.5510 \\
\hline 5 & $15-20$ & 2 & 100 & 0.0654 & 0.1307 & 3.5134 \\
\hline
\end{tabular}

For the test system in consideration, Voltage sensitivity index (VSI) values are calculated for zero wind power generation with the proposed OPF. Figure 3 shows the variation of VSI values with bus number. The highest VSI value of 0.0129 is obtained for bus number 18 , indicating that the DG should be placed at bus number 18 . 


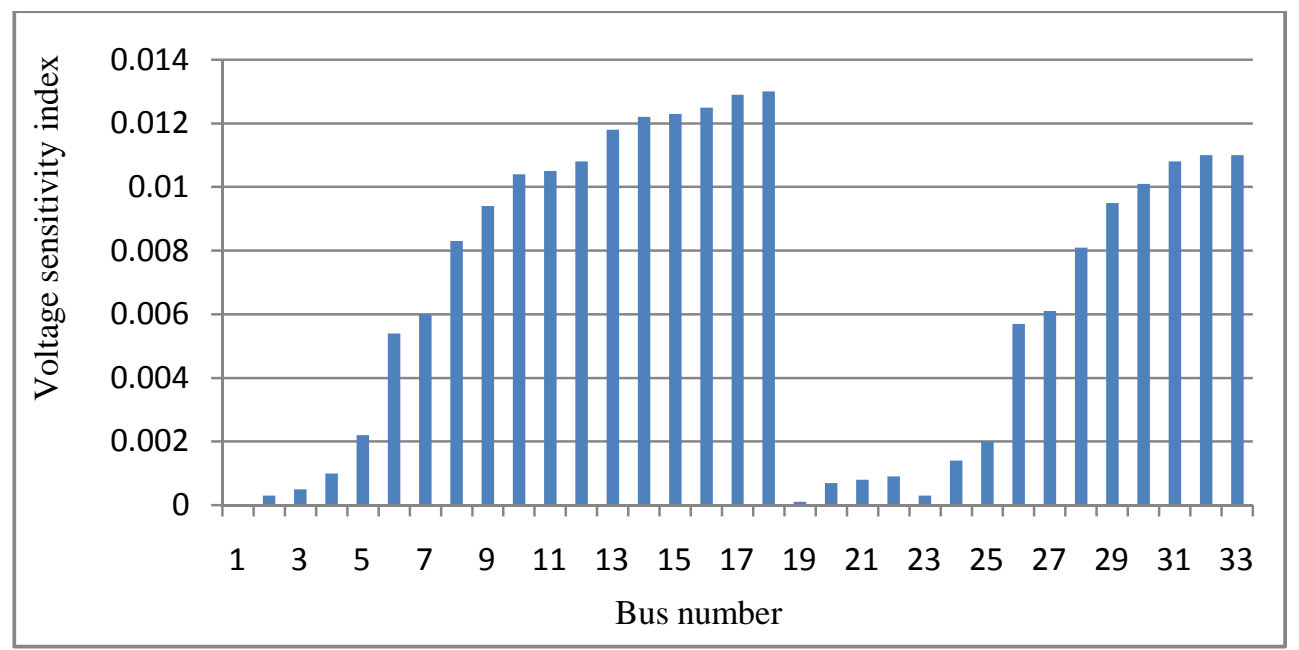

Figure3. Voltage sensitivity index(VSI) values for the nodes of 33 bus RDS

Table 3 shows the comparison of total active power loss (TPL) and the total reactive power loss (TQL) of the 33 bus RDS for various scenarios of wind turbine integration. Table 3 show the branch real power losses for the radial system when the wind turbine is placed at bus 18 for both CP and realistic ZIP loads.

Table 3. Comparison of TPL and TQL for various scenarios of wind turbine placement

\begin{tabular}{|c|l|l|l|l|}
\hline \multirow{2}{*}{$\begin{array}{c}\text { Level } \\
\text { index }\end{array}$} & \multicolumn{2}{|c|}{$\begin{array}{c}\text { Wind turbine placed at bus number 18 } \\
\text { with CP load }\end{array}$} & \multicolumn{2}{c|}{$\begin{array}{r}\text { Wind turbine placed at bus number 18 } \\
\text { with ZIP load }\end{array}$} \\
\cline { 2 - 5 } & \multicolumn{1}{|c|}{ TPL $(\mathrm{kW})$} & \multicolumn{1}{|c|}{ TQL $(\mathrm{kVAR})$} & \multicolumn{1}{|c|}{ TPL $(\mathrm{kW})$} & \multicolumn{1}{|c|}{ TQL (kVAR) } \\
\hline 0 & 140.9077 & 105.9969 & 131.4810 & 98.8677 \\
\hline 1 & 136.085 & 102.1101 & 131.4338 & 98.5986 \\
\hline 2 & 118.9697 & 88.5825 & 114.7703 & 85.436 \\
\hline 3 & 109.2605 & 81.2553 & 105.3886 & 78.3728 \\
\hline 4 & 116.5596 & 86.7284 & 112.4333 & 83.6412 \\
\hline 5 & 126.4778 & 94.4531 & 122.0666 & 91.1359 \\
\hline
\end{tabular}

Table 4. Nodal prices for radial system at wind level 3

\begin{tabular}{|c|c|c|c|c|c|c|c|c|c|}
\hline \multirow{2}{*}{$\begin{array}{l}\text { Bus } \\
\text { no: }\end{array}$} & \multicolumn{2}{|c|}{$\begin{array}{c}\mathrm{N}_{\mathrm{pi}} \\
(\$ / \mathrm{MWh})\end{array}$} & \multicolumn{2}{|c|}{$\begin{array}{c}\mathrm{N}_{\mathrm{Qi}} \\
\text { (\$/MVARh) }\end{array}$} & \multirow{2}{*}{$\begin{array}{l}\text { Bus } \\
\text { no: }\end{array}$} & \multicolumn{2}{|c|}{$(\$ / M W h){ }^{N_{p i}}$} & \multicolumn{2}{|c|}{$\begin{array}{c}\mathrm{N}_{\mathrm{Qi}} \\
\text { (\$/MVARh) }\end{array}$} \\
\hline & $\begin{array}{l}\text { Without } \\
\text { wind }\end{array}$ & $\begin{array}{l}\text { With } \\
\text { windlevel3 }\end{array}$ & $\begin{array}{l}\text { Without } \\
\text { wind }\end{array}$ & $\begin{array}{l}\text { With wind } \\
\text { level3 }\end{array}$ & & $\begin{array}{l}\text { Without } \\
\text { wind }\end{array}$ & $\begin{array}{l}\text { With wind } \\
\text { level3 }\end{array}$ & $\begin{array}{l}\text { Without } \\
\text { wind }\end{array}$ & $\begin{array}{l}\text { Without } \\
\text { wind } \\
\text { level } 3\end{array}$ \\
\hline 1 & 40.0771 & 40.0695 & 0 & 0 & 18 & 43.1824 & 41.6653 & 2.2922 & 1.1491 \\
\hline 2 & 40.0818 & 40.0723 & 0.0024 & 0.0014 & 19 & 40.0976 & 40.0853 & 0.0176 & 0.0139 \\
\hline 3 & 40.1063 & 40.0871 & 0.0151 & 0.0092 & 20 & 40.2117 & 40.1784 & 0.1207 & 0.0981 \\
\hline 4 & 40.3782 & 40.2717 & 0.1590 & 0.1066 & 21 & 40.2292 & 40.1927 & 0.1408 & 0.1145 \\
\hline 5 & 40.7355 & 40.5229 & 0.3406 & 0.2343 & 22 & 40.2427 & 40.2038 & 0.1587 & 0.1291 \\
\hline 6 & 41.3943 & 40.9921 & 0.9230 & 0.6481 & 23 & 40.1758 & 40.1439 & 0.0636 & 0.0487 \\
\hline
\end{tabular}


Table 4 (cont'd). Nodal prices for radial system at wind level 3

\begin{tabular}{|l|l|l|l|l|l|l|l|l|l|}
\hline \multirow{2}{*}{$\begin{array}{l}\text { Bus } \\
\text { no: }\end{array}$} & \multicolumn{2}{|c|}{$\begin{array}{c}\mathrm{N}_{\mathrm{pi}} \\
(\$ / \mathrm{MWh})\end{array}$} & \multicolumn{2}{|c|}{$\begin{array}{c}\mathrm{N}_{\mathrm{Qi}} \\
\text { Without } \\
\text { wind }\end{array}$} & $\begin{array}{l}\text { With } \\
\text { windlevel3 }\end{array}$ & $\begin{array}{l}\text { Without } \\
\text { wind }\end{array}$ & $\begin{array}{l}\text { With wind } \\
\text { level3 }\end{array}$ & & \multicolumn{2}{|c|}{$\begin{array}{l}\mathrm{N}_{\mathrm{pi}} \\
\text { no: }\end{array}$} & & $\begin{array}{l}\text { Without } \\
\text { wind }\end{array}$ & $\begin{array}{l}\text { With wind } \\
\text { level3 }\end{array}$ & $\begin{array}{l}\text { Without } \\
\text { wind }\end{array}$ & $\begin{array}{l}\text { Without } \\
\text { wind } \\
\text { level 3 }\end{array}$ \\
\hline 7 & 41.4208 & 41.0094 & 0.9937 & 0.6938 & 24 & 40.4120 & 40.3367 & 0.2511 & 0.2019 \\
\hline 8 & 42.0058 & 41.3281 & 1.4172 & 0.9239 & 25 & 40.5330 & 40.4355 & 0.3440 & 0.2778 \\
\hline 9 & 42.2866 & 41.4598 & 1.6156 & 1.0172 & 26 & 41.4989 & 41.0748 & 0.9576 & 0.6785 \\
\hline 10 & 42.5509 & 41.5758 & 1.8025 & 1.0993 & 27 & 41.6285 & 41.179 & 1.0239 & 0.7317 \\
\hline 11 & 42.6036 & 41.5942 & 1.8185 & 1.105 & 28 & 42.0487 & 41.5159 & 1.3993 & 1.0328 \\
\hline 12 & 42.6950 & 41.6227 & 1.8488 & 1.1144 & 29 & 42.3628 & 41.7678 & 1.6710 & 1.2506 \\
\hline 13 & 42.9593 & 41.7084 & 2.0580 & 1.182 & 30 & 42.5521 & 41.9198 & 1.7645 & 1.3257 \\
\hline 14 & 43.0204 & 41.728 & 2.1376 & 1.2076 & 31 & 42.6977 & 42.0364 & 1.9081 & 1.4408 \\
\hline 15 & 43.0380 & 41.7368 & 2.1529 & 1.2154 & 32 & 42.7254 & 42.0586 & 1.9395 & 1.4659 \\
\hline 16 & 43.1014 & 41.7227 & 2.1991 & 1.2052 & 33 & 42.7314 & 42.0634 & 1.9487 & 1.4733 \\
\hline 17 & 43.1553 & 41.7024 & 2.2712 & 1.1783 & & & & & \\
\hline
\end{tabular}

Table 5. Npi values for various levels with wind turbine

\begin{tabular}{|l|l|l|l|l|l|l|}
\hline $\begin{array}{l}\text { Line } \\
\text { no: }\end{array}$ & w/o Wind & Level 1 & Level 2 & Level 3 & Level 4 & Level 5 \\
\hline 1 & 40.0771 & 40.0762 & 40.0724 & 40.0695 & 40.0718 & 40.0742 \\
\hline 2 & 40.0818 & 40.0801 & 40.0756 & 40.0723 & 40.0748 & 40.0777 \\
\hline 3 & 40.1063 & 40.1007 & 40.0924 & 40.0871 & 40.0911 & 40.0961 \\
\hline 4 & 40.3782 & 40.3328 & 40.2942 & 40.2717 & 40.2887 & 40.3112 \\
\hline 5 & 40.7355 & 40.6388 & 40.5649 & 40.5229 & 40.5544 & 40.5973 \\
\hline 6 & 41.3943 & 41.2039 & 41.0676 & 40.9921 & 41.0487 & 41.1271 \\
\hline 7 & 41.4208 & 41.2264 & 41.0867 & 41.0094 & 41.0673 & 41.1477 \\
\hline 8 & 42.0058 & 41.7152 & 41.4704 & 41.3281 & 41.4355 & 41.5783 \\
\hline 9 & 42.2866 & 41.9469 & 41.6409 & 41.4598 & 41.5968 & 41.7761 \\
\hline 10 & 42.5509 & 42.1639 & 41.7961 & 41.5758 & 41.7428 & 41.959 \\
\hline 11 & 42.6036 & 42.2065 & 41.8241 & 41.5942 & 41.7686 & 41.9936 \\
\hline 12 & 42.695 & 42.2801 & 41.8704 & 41.6227 & 41.8108 & 42.0522 \\
\hline 13 & 42.9593 & 42.4929 & 42.006 & 41.7084 & 41.9347 & 42.2224 \\
\hline 14 & 43.0204 & 42.542 & 42.037 & 41.728 & 41.963 & 42.2615 \\
\hline 15 & 43.038 & 42.5565 & 42.0479 & 41.7368 & 41.9734 & 42.274 \\
\hline 16 & 43.1014 & 42.6028 & 42.058 & 41.7227 & 41.978 & 42.3005 \\
\hline 17 & 43.1553 & 42.6411 & 42.061 & 41.7024 & 41.9756 & 42.3194 \\
\hline 18 & 43.1824 & 42.6565 & 42.0452 & 41.6653 & 41.9549 & 42.3177 \\
\hline 19 & 40.0976 & 40.0939 & 40.0888 & 40.0853 & 40.0879 & 40.0911 \\
\hline 20 & 40.2117 & 40.1933 & 40.1834 & 40.1784 & 40.1821 & 40.1877 \\
\hline & & & & & & \\
\hline
\end{tabular}


Table 5 (cont'd). Npi values for various levels with wind turbine

\begin{tabular}{|l|l|l|l|l|l|l|}
\hline $\begin{array}{l}\text { Line } \\
\text { no: }\end{array}$ & w/o Wind & Level 1 & Level 2 & Level 3 & Level 4 & Level 5 \\
\hline 21 & 40.2292 & 40.2086 & 40.1979 & 40.1927 & 40.1965 & 40.2025 \\
\hline 22 & 40.2427 & 40.2204 & 40.2092 & 40.2038 & 40.2077 & 40.214 \\
\hline 23 & 40.1758 & 40.1613 & 40.1501 & 40.1439 & 40.1485 & 40.155 \\
\hline 24 & 40.412 & 40.3671 & 40.346 & 40.3367 & 40.3434 & 40.3549 \\
\hline 25 & 40.533 & 40.4726 & 40.4464 & 40.4355 & 40.4432 & 40.4573 \\
\hline 26 & 41.4989 & 41.2947 & 41.1526 & 41.0748 & 41.133 & 41.2146 \\
\hline 27 & 41.6285 & 41.4075 & 41.2591 & 41.179 & 41.2388 & 41.3236 \\
\hline 28 & 42.0487 & 41.7729 & 41.6039 & 41.5159 & 41.5811 & 41.6769 \\
\hline 29 & 42.3628 & 42.0461 & 41.8616 & 41.7678 & 41.837 & 41.941 \\
\hline 30 & 42.5521 & 42.2107 & 42.017 & 41.9198 & 41.9914 & 42.1002 \\
\hline 31 & 42.6977 & 42.3373 & 42.1364 & 42.0364 & 42.1099 & 42.2225 \\
\hline 32 & 42.7254 & 42.3614 & 42.1591 & 42.0586 & 42.1325 & 42.2458 \\
\hline 33 & 42.7314 & 42.3666 & 42.164 & 42.0634 & 42.1374 & 42.2508 \\
\hline
\end{tabular}

Table 6. Nqi values for various levels with wind turbine Normal (CP) load in radial system

\begin{tabular}{|l|l|l|l|l|l|l|}
\hline $\begin{array}{l}\text { Line } \\
\text { no: }\end{array}$ & $\begin{array}{l}\text { w/o } \\
\text { Wind }\end{array}$ & Level 1 & Level 2 & Level 3 & Level 4 & Level 5 \\
\hline 1 & 0 & 0 & 0 & 0 & 0 & 0 \\
\hline 2 & 0.0024 & 0.002 & 0.0016 & 0.0014 & 0.0016 & 0.0018 \\
\hline 3 & 0.0151 & 0.0127 & 0.0104 & 0.0092 & 0.0101 & 0.0114 \\
\hline 4 & 0.1590 & 0.1355 & 0.117 & 0.1066 & 0.1144 & 0.1251 \\
\hline 5 & 0.3406 & 0.291 & 0.2546 & 0.2343 & 0.2495 & 0.2705 \\
\hline 6 & 0.9230 & 0.7905 & 0.6983 & 0.6481 & 0.6856 & 0.7384 \\
\hline 7 & 0.9937 & 0.8503 & 0.7489 & 0.6938 & 0.735 & 0.793 \\
\hline 8 & 1.4172 & 1.204 & 1.0263 & 0.9239 & 1.0011 & 1.1044 \\
\hline 9 & 1.6156 & 1.3677 & 1.1469 & 1.0172 & 1.1153 & 1.2443 \\
\hline 10 & 1.8025 & 1.5213 & 1.2568 & 1.0993 & 1.2186 & 1.3737 \\
\hline 11 & 1.8185 & 1.5343 & 1.2654 & 1.105 & 1.2266 & 1.3844 \\
\hline 12 & 1.8488 & 1.5586 & 1.2807 & 1.1144 & 1.2405 & 1.4038 \\
\hline 13 & 2.0580 & 1.727 & 1.3877 & 1.182 & 1.3383 & 1.5383 \\
\hline 14 & 2.1376 & 1.791 & 1.4283 & 1.2076 & 1.3754 & 1.5893 \\
\hline 15 & 2.1529 & 1.8036 & 1.4378 & 1.2154 & 1.3845 & 1.6002 \\
\hline 16 & 2.1991 & 1.8374 & 1.4452 & 1.2052 & 1.3878 & 1.6195 \\
\hline 17 & 2.2712 & 1.8884 & 1.4493 & 1.1783 & 1.3847 & 1.6447 \\
\hline 18 & 2.2922 & 1.9005 & 1.4369 & 1.1491 & 1.3685 & 1.6434 \\
\hline 19 & 0.0176 & 0.0153 & 0.0143 & 0.0139 & 0.0141 & 0.0147 \\
\hline 20 & 0.1207 & 0.1051 & 0.0998 & 0.0981 & 0.0992 & 0.102 \\
\hline 21 & 0.1408 & 0.1226 & 0.1165 & 0.1145 & 0.1158 & 0.119 \\
\hline 22 & 0.1587 & 0.1382 & 0.1313 & 0.1291 & 0.1306 & 0.1341 \\
\hline 23 & 0.0636 & 0.0549 & 0.0506 & 0.0487 & 0.0501 & 0.0524 \\
\hline
\end{tabular}


Table 6 (cont'd). Nqi values for various levels with wind turbine Normal (CP) load in radial system

\begin{tabular}{|l|l|l|l|l|l|l|}
\hline $\begin{array}{l}\text { Line } \\
\text { no: }\end{array}$ & $\begin{array}{l}\text { w/o } \\
\text { Wind }\end{array}$ & Level 1 & Level 2 & Level 3 & Level 4 & Level 5 \\
\hline 24 & 0.2511 & 0.2184 & 0.2062 & 0.2019 & 0.2048 & 0.2112 \\
\hline 25 & 0.3440 & 0.2994 & 0.2833 & 0.2778 & 0.2815 & 0.2898 \\
\hline 26 & 0.9576 & 0.8209 & 0.7285 & 0.6785 & 0.7158 & 0.7686 \\
\hline 27 & 1.0239 & 0.8785 & 0.7829 & 0.7317 & 0.7698 & 0.8244 \\
\hline 28 & 1.3993 & 1.2051 & 1.0909 & 1.0328 & 1.0757 & 1.14 \\
\hline 29 & 1.6710 & 1.4413 & 1.3138 & 1.2506 & 1.2971 & 1.3684 \\
\hline 30 & 1.7645 & 1.5226 & 1.3906 & 1.3257 & 1.3733 & 1.447 \\
\hline 31 & 1.9081 & 1.6475 & 1.5083 & 1.4408 & 1.4902 & 1.5677 \\
\hline 32 & 1.9395 & 1.6748 & 1.5341 & 1.4659 & 1.5158 & 1.5941 \\
\hline 33 & 1.9487 & 1.6828 & 1.5416 & 1.4733 & 1.5233 & 1.6019 \\
\hline
\end{tabular}

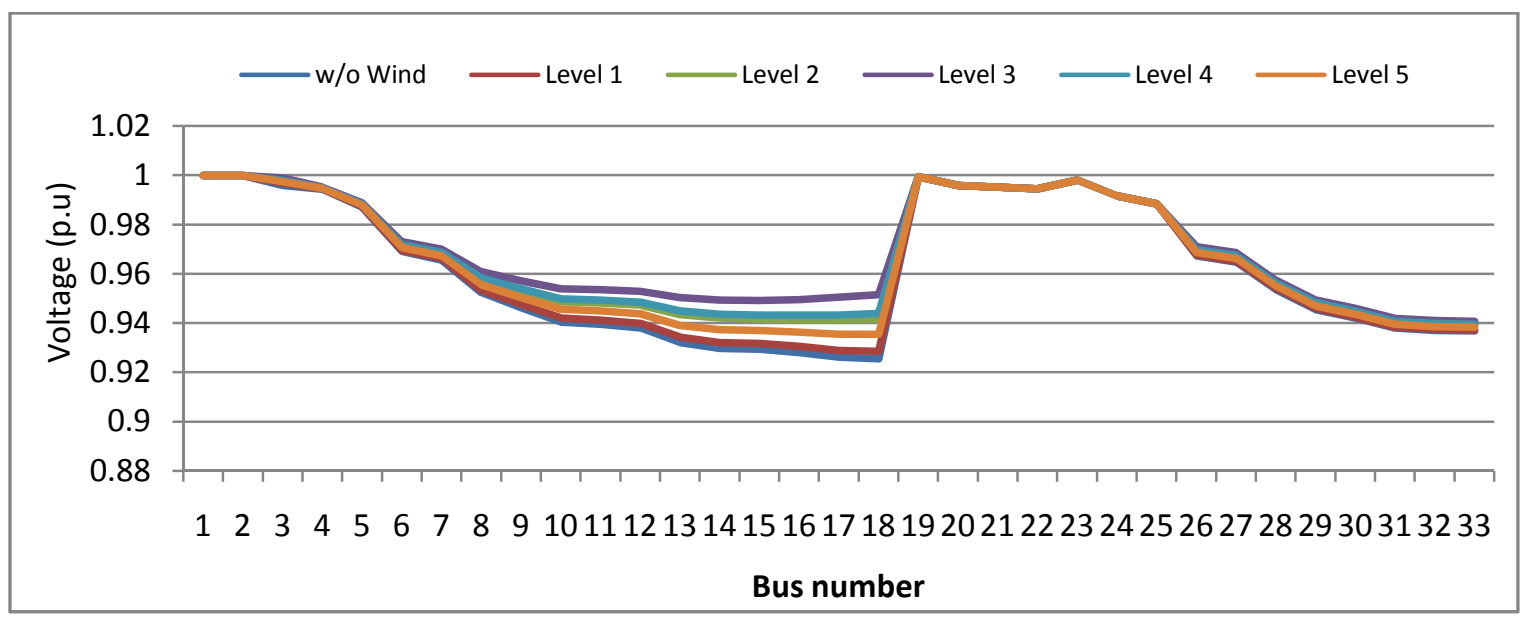

Figure4. Voltage profile for various levels with wind turbine placed at bus 18 with CP load in radial system

Table 4 shows the active and reactive power nodal prices with and without wind integration at wind level 3 . As at wind level 3 , the losses are observed minimum. The power output of the wind turbine is more compared to other levels. Tables 5 and 6 show the comparison of active and reactive power nodal prices for various scenarios of wind power available in the system. From these results, it can be observed that the active and reactive power losses get reduced with the integration of wind turbines. The TPL for level 0, or without the integration of wind turbine, is $140.9077 \mathrm{~kW}$. Similarly, the TQL for level 0 is $105.9969 \mathrm{kVAR}$. These values are significantly reduced by placing the wind turbines. For example, the value of TPL after placing wind turbine reduces to a minimum of $109.2605 \mathrm{~kW}$ when the wind turbine is placed at bus 18. The value of TQL after placing wind turbine reduces to a minimum of $81.2553 \mathrm{kVAR}$ when the wind turbine is placed at bus 18. For ZIP load, the TPL for level 0, or without the integration of wind turbine, is $131.4810 \mathrm{~kW}$. Similarly, the TQL for level 0 is $98.8677 \mathrm{kVAR}$. These values are reduced to $105.3886 \mathrm{~kW}$ and $78.3728 \mathrm{kVAR}$ respectively. Among all scenarios level3 is giving better results due to its high power output. So, all the results compared below were taken for level 3 scenario. Voltage profile with wind level is shown in Figure 4. It is observed that with wind integration, the voltage profile has improved.

The wind power output for different speed range is given in Table 7. The wind power output, probability of occurrence, and penetration level of the wind power is also given in the table. Loss profile with wind integration is shown in Fig. 5 for all levels of wind power available. It is observed that the branch losses reduce with all levels of wind generation. With reduction in the losses, there is reduction in the marginal loss coefficients and thereby reduction in both the real and reactive power marginal prices. 
Table 7. Wind speed levels and the corresponding power outputs

\begin{tabular}{|c|c|c|c|c|c|c|}
\hline $\begin{array}{c}\text { Level } \\
\text { index }\end{array}$ & $\begin{array}{c}\text { Speed } \\
\text { range } \\
(\mathrm{m} / \mathrm{s})\end{array}$ & $\begin{array}{c}\text { Mean power } \\
\text { output } \\
(\mathrm{MW})\end{array}$ & $\begin{array}{c}\text { Percentage of rated } \\
\text { turbine power output } \\
(\%)\end{array}$ & $\begin{array}{c}\text { Probability } \\
\text { of } \\
\text { occurrence }\end{array}$ & $\begin{array}{c}\text { Actual power } \\
\text { output (MW) }\end{array}$ & $\begin{array}{l}\text { Penetration } \\
\text { level (\%) }\end{array}$ \\
\hline 0 & $0-3$ & 0 & 0 & 0.1416 & 0 & 0.0000 \\
\hline 1 & $3-5$ & 0.2408 & 12.0399 & 0.1683 & 0.0405 & 1.0887 \\
\hline 2 & $5-8$ & 0.8108 & 40.5411 & 0.2636 & 0.2137 & 5.7446 \\
\hline 3 & $8-11.5$ & 1.5564 & 77.8208 & 0.225 & 0.3502 & 9.4139 \\
\hline 4 & $11.5-15$ & 2 & 100 & 0.1219 & 0.2437 & 6.5510 \\
\hline 5 & $15-20$ & 2 & 100 & 0.0654 & 0.1307 & 3.5134 \\
\hline
\end{tabular}

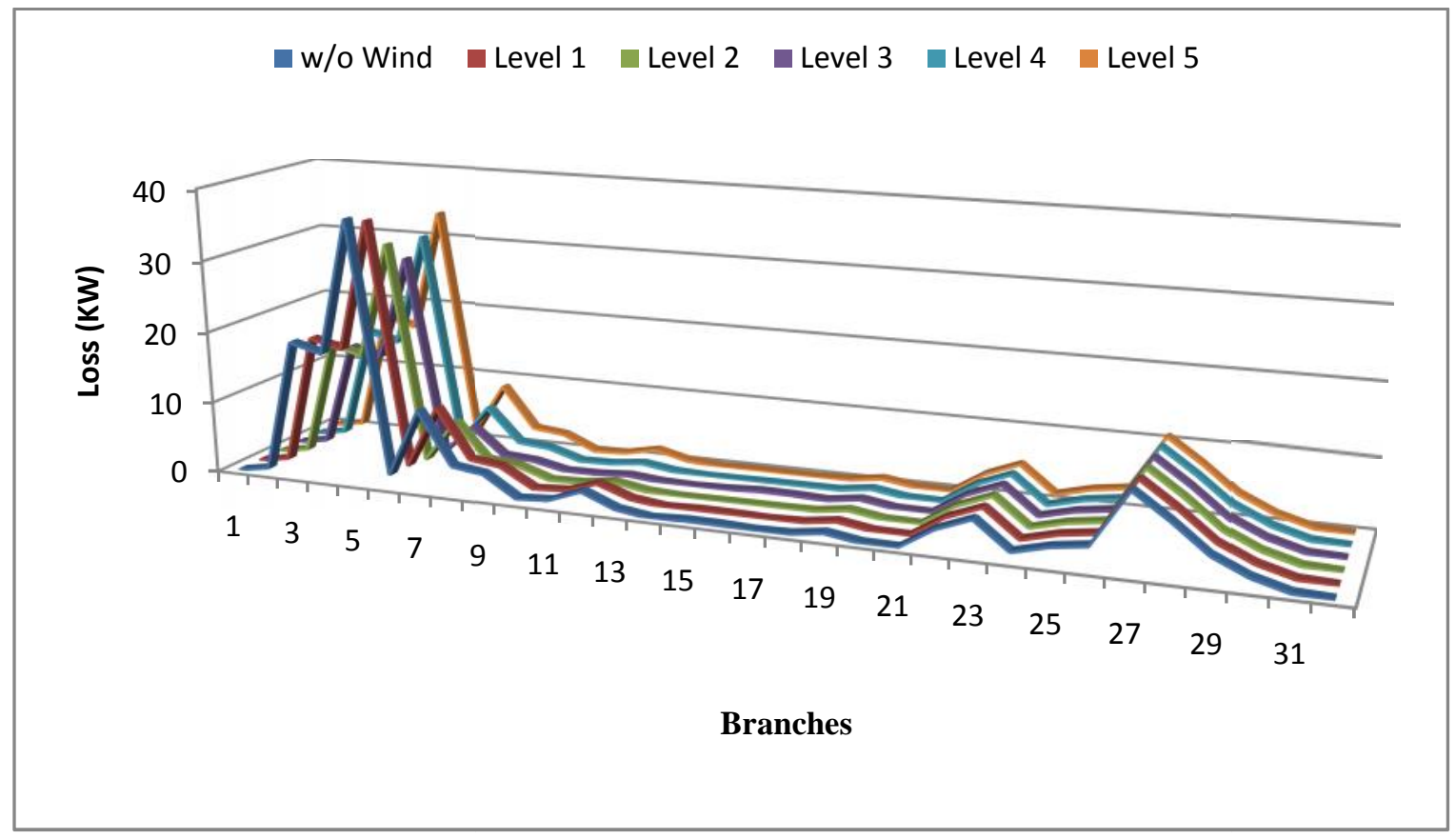

Figure 5. Branch real power losses for various levels with wind turbine for CP load in radial system

\section{Conclusions}

In this study, the impacts of wind power integration on the optimal nodal pricing of distribution systems were discussed for radial system. The variability of wind power output is observed to cause noteworthy deviations in the nodal prices of the distribution system. These deviations are important as the volatility of wind power outputs leads to volatility in the nodal prices of the system. There is reduction in the all branches with wind integration and due to reduction in the losses, there is reduction in the marginal loss coefficients and nodal prices. The active and reactive power nodal prices of the distribution system are oberved lower with the integration of wind turbines into the system.

\section{References}

De Oliveira-De Jesus P. M., Ponce de Leao M. T., 2005. Cost of loss allocation in distribution networks with high penetration of distributed renewable generation - a comparative study. International Conference on Renewable Energy and Power Quality, Zaragoza: 2005.

Ghayeni. M., Ghazi. R., 2011. Transmission network cost allocation with nodal pricing approach based on ramsay pricing concept. IET Generation, Transmission \& Distribution, Vol.5, pp. 384-392.

Li R., Wu Q., Oren S. S., 2014. Distributional locational marginal pricing for optimal electric vehicle charging management. IEEE Transactions on Power Systems, Vol. 29, pp. 203-211.

Murthy V. V. S. N., Kumar A., 2014. Mesh distribution system analysis in presence of distributed generation with time varying load model. International Journal of Electrical Power \& Energy Systems, Vol.62, pp. 836-854.

Mutale J., Strbac G., Curcic. S., Jenkins. N., 2000. Allocation of losses in distribution systems with embedded generation. IEE Proceedings - Generation, Transmission and Distribution, Vol.147, pp. 7-14. 
O’Connell N., Wu Q., Ostergaard J., Nielsen A. H., Cha S. T., Ding Y. , 2012. Day ahead tariff for the allevation of distribution grid congestion from electric vehicles. Electric Power Systems Research, Vol.92, pp. 106-114.

Polisetti K., Kumar A., 2016. Distribution system nodal prices determination for realistic ZIP and seasonal loads: An optimal power flow approach. Procedia Technology, Vol.25, pp.702-709.

Singh R. K., Goswami S. K., 2006. Optimal allocation of distributed generations based on nodal pricing for profit, loss reduction and voltage improvement including voltage rise issue. International Journal of Electrical Power \& Energy Systems, Vol.32, pp. 637-644.

Sooraj N.K., Kumar A., 2015. Distribution system nodal pricing analysis with realistic ZIP load and variable wind power source. 2015 Annual IEEE India Conference (INDICON), DOI: 10.1109/INDICON.2015.7443140.

Sotkiewicz. P. M., Vignolo J. M., 2007. Towards a cost causation-based tariff for distribution network with DG. IEEE Transactions on Power Systems, Vol. 22, pp. 1051-1060.

Sotkiewicz P. M., Vignolo J. M., 2006. Nodal pricing for distribution networks: efficient pricing for efficiency enhancing DG. IEEE Transactions on Power Systems, Vol.21, pp.1013-1014.

Sotkiewicz P. M., Vignolo J. M., 2012. The value of intermittent wind DG under nodal prices and amp - mile tariffs. Transmission and Distribution: Latin America Conference and Exposition (T\&D-LA), 2012 Sixth IEEE/PES, pp.1-7.

Zhao Q., Wang P., Ding Y., Goel L.K., 2010. Impacts of solar power penetration on nodal prices and nodal reliability. 2010 Conference Proceedings IPEC, pp.1134-1139.

Zhao Q., Wang P., Goel L., Ding Y., 2011. Impacts of renewable energy penetration on nodal price and nodal reliability in deregulated power system. IEEE Power and Energy Society General Meeting, pp.1-6.

Received September 2016

Accepted November 2016

Final acceptance in revised form June 2017 